\title{
Reducing Bias in Faculty Searches
}

\section{Elizabeth A. Burroughs}

\author{
Communicated by Stephen Kennedy
}

Historically, women and individuals from marginalized populations have been underserved by the discipline of mathematics, with the result that the knowledge and talents of these individuals have not been available to enrich the discipline. Across the mathematical community, there is a growing awareness about the need and opportunity to foster diversity. Individuals with diverse backgrounds can provide a department with new research perspectives or methods that enhance the research work of faculty with similar interests, and may attract more diverse students and collaborators. These contributions to diversity can fulfill underlying goals of a department in reaching more students and generating new mathematical knowledge.

\section{What Is Implicit Bias?}

Implicit bias is the phenomenon where a stereotype influences a person's decisions without his or her awareness. Because the stereotype operates without a person's awareness, it takes conscious effort to overcome this implicit bias [2]. There is a wide base of research literature documenting implicit bias and studying its effects on hiring, including in academia. Social-psychology research has identified implicit bias based on a variety of stereotypes: gender bias, ethnic or racial bias, motherhood bias, sexuality bias, and disability bias have all been documented.

Elizabeth A. Burroughs is professor and head of the Department of Mathematical Sciences at Montana State University. Her email address is burroughs@montana.edu.

${ }^{1}$ In 2012 Montana State received an NSF ADVANCE award (no. 1208831) to increase the recruitment, retention, and advancement of women in STEM disciplines across campus. See the October 7, 2016 Chronicle of Higher Education. In 2015, Maria Klawe [1] issued a call in the Notices to talk about gender equality in mathematics.

For permission to reprint this article, please contact: reprint-permission@ams .org.

DOI: http://dx.doi.org/10.1090/noti1600

\section{What Montana State Does}

There are two foci in Montana State University's plan ${ }^{1}$ to increase diversity in faculty hires:

(1) recognizing that everyone holds unintentional biases that can influence our evaluation of applicants; and

(2) purposefully focusing on recruitment to create a pool of applicants who are well-qualified and from diverse backgrounds.

The university focuses on search committee training as a tool to give practical strategies to address both aspects of this plan. Other programming across campus, such as guest speakers and campus community discussions, have provided a forum to discuss the underlying reasons that having diversity on campus can be valuable.

\section{Search Committee Training}

The training consists of a thorough handbook and a one-hour training, conducted by a faculty member and an HR representative, to make committee members conscious of biases and understand ways to work to overcome them in evaluation and decision-making. The overarching message of this training is that an awareness of bias reduces its effect. As committee members, simply reminding ourselves that we are prone to a bias can reduce the effect of the bias.

Search committees are encouraged to consider diversity as an asset and use it as one of many criteria in evaluation.
Everyone holds unintentional biases that can influence our evaluation.
The materials remind committees that anyone can demonstrate a commitment to creating an inclusive workplace, and infusing diversity into the search process can help to hire a faculty member who values and respects difference, no matter his or her identity. There is no expecta- 
... awareness

of bias reduces its effect. tion that searches will hire under-qualified applicants just to satisfy a diversity goal. The search training directly addresses potential fears of search committees that their consideration of diversity will somehow prevent them from selecting the "best" candidate by some objective measure, such as the number of publications or grant dollars. Many factors usually prevent such a candidate from being deemed the best-for example, if a candidate's area of expertise overlaps too much with existing faculty members' research, or if it doesn't match a department's existing research program enough. The training provides the advice that in cases where a department lacks diversity, a candidate who adds diversity may be the best candidate overall for the program because of the benefit that diversity itself affords.

The final advice is that because stereotypes are mental shortcuts, one way to combat the bias from stereotypes is to take time. Rushing through a review of materials is more likely to activate stereotypes, so allow each application a careful review. In academic life, there are many competing demands, and it can be easy to try to minimize time on committee work. But search committee members must make a commitment to investing the time it takes to complete a search that won't rely on quick judgments. Committee members can focus on whom to include rather than whom to exclude, and be sure to articulate a reason to advance or exclude someone. Making that decision public gives other committee members the opportunity to weigh in and serve as a check that the decision is not based in bias.

\section{Recruitment}

The key to being able to hire diverse candidates is getting those diverse candidates to apply for the open position. The strategies we use are focusing on the wording of the advertisement, advertising in venues that appeal to diverse candidates, and personally reaching out to encourage candidates to apply.

The wording of the announcement should be carefully considered, with a focus on broad descriptions of areas rather than a narrow focus. This is based on research from psychology: "On average, men apply for a job when they meet only $60 \%$ of the qualifications. Women apply only when they meet $90 \%$ of them" [3]. In our department, we have focused on broad descriptions of research areas. We also include our desire for diversity in the position advertisement, for example, by including language such as, "We hope to attract applicants who are committed to helping students from diverse backgrounds succeed."

The materials also caution against making assumptions about a candidate's motivation or interest in an opening. Making inferences like, "She lives in a big city so she won't be interested in our position," or, "She will have offers at more prestigious universities so wouldn't really consider an offer from us," only undermine our efforts to recruit for diversity. Our obligation is to recruit broadly into the search pool, and then let the candidates decide if they want the position.

We advertise in publications and websites that target women and minorities. In the mathematical sciences, available options are the Association for Women in Mathematics, the Benjamin Banneker Association, TODOS, the National Association of Mathematicians, the Society for the Advancement of Chicanos/Hispanics and Native Americans in Science, and the Caucus for Women in Statistics.

We are also encouraged to use personal invitations to encourage applications. Montana State challenges each search committee member to personally contact ten potential applicants with a "we'd love to review your materials" phone call or email.

\section{Equity Advocate}

We do not rely exclusively on departmental committee members to combat the effects of bias. The university has initiated a program called the Equity Advocate program. Equity Advocates are faculty members from across campus who have attended additional training to learn about recognizing and preventing bias. These individuals are available to serve on search committees in any department. We have had two Equity Advocates who are members of our department, but we have also had Equity Advocates from other departments serve on our search committees. Though every member of the search committee attends the search committee training, which includes the materials about bias and acting against bias, it is useful to have someone whose responsibility on the committee is to recognize potential bias.

Equity Advocates can often speak up when a departmental colleague might not. Imagine being one of the few women in a department and serving on a search committee. These three underlying assumptions are unfair and not necessarily true:

(i) because you are a woman it is your job to recognize bias,

(ii) it is your responsibility to alert the committee to bias, and

(iii) decisions you make are not based on bias.

There's also an additional mental tax that comes from not only fulfilling the usual obligations of the committee, but also having to be attuned to everyone's choices and statements and screen them for potential bias. This is an unreasonable burden on women who serve on committees-an already high-workload assignment. The practice of committee training for all, with the expectation that all members of a committee will be alert for their own bias and actively work against it, combined with the use of 
Equity Advocates, whose only role can be to be alert for potential bias, results in a stronger committee structure.

\section{Family Advocate Meetings during Interview}

One component of the interview visits that has become standard on our campus is a visit with the University Family Advocate. The Family Advocate is a tenured faculty member who has been appointed to serve the university by disseminating information about resources and policies affecting families on campus.

The Family Advocate has responsibilities for work with current employees, but also participates in the recruitment process. She is completely separate from the search committee, offers no feedback to the department or to the hiring committee, and is able to hold confidential meetings with every candidate. The meetings have a standard format: they last twenty to thirty minutes, and they open with the Family Advocate describing the programs on campus that support work-life balance, such as on-campus preschool, employee wellness benefits, and stop-the-clock tenure policies. There is always time for open question and answer, and it is often here that the candidate asks questions about dual-career partner accommodations or asks questions about the campus climate.

Our department has found these visits are useful as a recruiting tool, but also as an honest reflection of our department's values. As a group, we intend to support our faculty candidates, and it is a relief to know that they can have open and frank conversations early in the process and get advice and answers from someone knowledgeable on campus.

I have occasionally served as a Family Advocate for candidates in searches from other departments or colleges, and I've seen how much candidates value this time. I've had conversations about schools for children, about opportunities for partner employment on campus and in the region, and about quality of life in general in Bozeman.

\section{Dual-Career Arrangements}

Most everyone who has been involved in an academic search is aware of the two-body problem, where a candidate has a partner or spouse who is also looking for an academic position. At Montana State, we are particularly sensitive that while we live in a vibrant community with an appealing natural setting, we are in a small city in a rural state bordered by other rural states. We begin all searches with the recognition that nearly all faculty candidates will come with a spouse or partner, and that person will also need to find meaningful employment. We acknowledge that we can't leave the partners to fend for themselves in finding a new job, as might be reasonable in an institution in a larger city. We also recognize that in the case that the partner is an academic, we have the opportunity to secure a dual-career couple. MSU has found that we can identify a two-body opportunity rather than problem.

The mechanics of how this works vary. Sometimes there is a tenure-track opening in a suitable department; other times we are authorized to pursue a target-of-opportunity hire, where a tenure-track position is authorized to accommodate the partner. It is comparatively simpler to arrange for a non-tenure-track appointment. It is cooperation and effort at the deans' level, with partnerships across colleges, that make the system work. It doesn't always work, but it often does.

From a search committee member and department head perspective, the sooner the candidate declares the desire for an academic position for a partner, the easier it is to arrange and more likely it is to succeed. Early declaration perhaps flies in the face of advice many candidates have historically been given by their advisors and mentors, and many candidates often wait until the relative last minute to seek an accommodation. We rely on our advertising and the Family Advocate program to assure candidates of our sincere desire to accommodate two-body opportunities.

\section{Changes at the Departmental Level}

These initiatives have had an effect at MSU. Since 2012, the university has hired 72 faculty members in STEM departments. Of those 72 positions, 36 have been filled by women. Our own department has made twelve hires at the assistant professor level since 2013, and six of those new faculty members are women, in contrast to only three women among the thirteen tenured faculty.

We've seen results beyond simply quantifying new hires at the department level as well. One difference I have noticed is that the search committee training gives the committee permission to discuss potential sources of bias. Having the search materials gives us a starting place for these conversations about bias. It has also given us a venue for discussions about diversity and the advantages that having students and colleagues with diverse perspectives brings to our department. In the past, it has been simple to lament our lack of diversity and blame the lack of diversity within mathematics as a whole; now, we have knowledge and strategies that can help us to achieve a more diverse faculty.

There is the secondary effect that we have an increased awareness of the effects of bias in teaching. We had a department-wide discussion of how gendered perceptions of mathematicians affect individuals in our department. The immediate result was an awareness of how many women receive anonymous comments on course evaluations that refer to their appearance or contain sexual innuendos. It was a bit sad for everyone to realize that the women were not surprised to have had these experiences, and that the men were surprised that women have these experiences. This collective recognition of the gender bias in instruments has led to a discussion of how the department might deemphasize the use of this type of instrument, and focus on better evaluation through more time and care. Of course, the broader issue of how to address the biased expectations that students bring to the classroom won't be fixed by changing how we measure teaching effectiveness. Our department and the individuals in it continue to wrestle with issues of diversity as we consider our responsibility to reduce the effects of bias.

Note: MSU maintains a two-page summary of search tips as well as the faculty-search toolkit, which is 


\section{COMMUNICATION}

available by request to the email address on the page www.montana.edu/nsfadvance. Both are influenced by the work of Fine and Handlesman [4]. The documents on the webpage are freely provided for your use after registration. You can also purchase the toolkit from Wisconsin.

\section{References}

[1] MARIA KLAWE, Time to talk about gender equality in math? Notices Amer. Math. Soc. 62 (2015).

[2] Cheryl StaAts AND Charles Patton, "State of the Science: Implicit Bias Review 2013," Kirwan Institute for the Study of Race and Ethnicity (2013). Retrieved from www. kirwaninstitute.osu.edu/reports/2013/03_2013_SOTS-Implicit_Bias.pdf.

[3] T.S. MoHR, Why women don't apply for jobs unless they're 100\% qualified, Harvard Business Review (2014).

[4] E. Fine AND J. HANDELSMAN, Searching for Excellence \& Diversity $^{\oplus:}$ A Guide for Search Committees-National Edition. Women in Science and Engineering Leadership Institute, University of Wisconsin-Madison (2012), wiseli .engr.wisc. edu/searchguidebooks.php.

\section{ABOUT THE AUTHOR}

Elizabeth A. Burroughs has spent the past decade researching issues relevant to the teaching of $\mathrm{K}-12$ mathematics. She has overseen faculty searches as a committee chair and department head. In 2014-2015 she lived with her family in York, UK, while a Fulbright Scholar at the University of York.

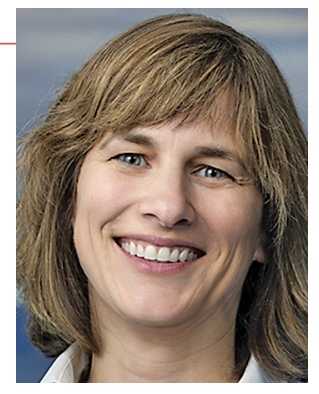

Elizabeth A. Burroughs

\section{Recent volumes from MSJ}

Advanced Studies in Pure Mathematics http://mathsoc.jp/publication/ASPM/

\section{Volume 73 \\ Hyperbolic Geometry and Geometric Group Theory \\ Edited by K. Fujiwara (Tohoku), \\ S. Kojima (Tokyo Tech), \\ K. Ohshika (Osaka) \\ ISBN 978-4-86497-042-6 \\ Volume 72 \\ Geometry, Dynamics, and Foliations 2013}

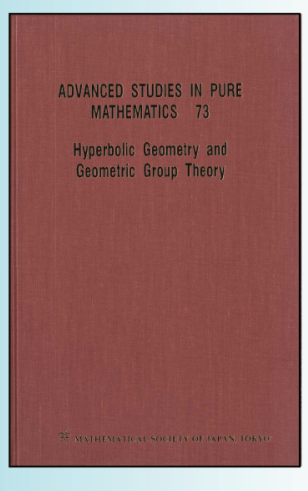

Edited by T. Asuke (Tokyo),

S. Matsumoto (Nihon), Y. Mitsumatsu (Chuo)

ISBN 978-4-86497-040-2

\section{Volume 71}

\section{Schubert Calculus - Osaka 2012}

Edited by H. Naruse (Yamanashi),

T. Ikeda (Okayama Sci.), M. Masuda (Osaka City),

T. Tanisaki (Osaka City)

ISBN 978-4-86497-038-9

MSJ Memoirs http://mathsoc.jp/publication/memoir/memoirs-e.html

\section{Volume 35 \\ Foundations of \\ the minimal model \\ program \\ Osamu Fujino \\ ISBN 978-4-86497-045-7}

Volume 34

Discrete Geometric

Analysis

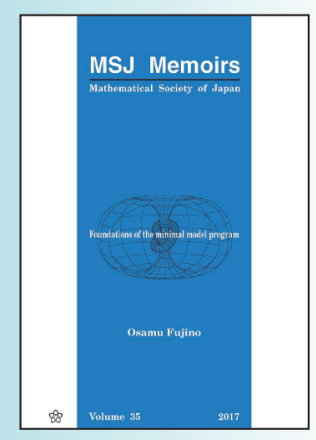

Martin T. Barlow, Tibor Jordán,

Andrzej Zuk

ISBN 978-4-86497-035-8

$\nabla \nabla \nabla$ For purchase, visit $\nabla \nabla \nabla$

http://www.ams.org/bookstore/aspmseries http://www.worldscientific.com/series/aspm http://www.worldscibooks.com/series/msjm

The Mathematical Society of Japan 34-8, Taito 1-chome, Taito-ku

Tokyo, JAPAN

http://mathsoc.jp/en/ 